\title{
BMJ Open Effectiveness of a targeted lifestyle intervention in primary care on diet and physical activity among South Asians at risk for diabetes: 2-year results of a randomised controlled trial in the Netherlands
}

\author{
Everlina M A Vlaar, ${ }^{1,2}$ Vera Nierkens, ${ }^{1,3}$ Mary Nicolaou, ${ }^{1}$ Barend J C Middelkoop, ${ }^{3}$ \\ Wim B Busschers, ${ }^{1}$ Karien Stronks, ${ }^{1}$ Irene G M van Valkengoed ${ }^{1}$
}

To cite: Vlaar EMA, Nierkens V, Nicolaou M, et al. Effectiveness of a targeted lifestyle intervention in primary care on diet and physical activity among South Asians at risk for diabetes: 2-year results of a randomised controlled trial in the Netherlands. BMJ Open 2017;7:e012221. doi:10.1136/ bmjopen-2016-012221

- Prepublication history and additional material is available. To view please visit the journal (http://dx.doi.org/ 10.1136/ bmjopen-2016-012221).

Received 12 April 2016

Revised 12 July 2016

Accepted 28 September 2016

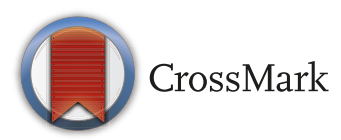

${ }^{1}$ Public Health, AMC, Amsterdam, The Netherlands

${ }^{2}$ GGD Flevoland, Lelystad, The Netherlands

${ }^{3}$ Public Health and Primary Health Care, Leiden Unversity Medical Center, Leiden, The Netherlands

Correspondence to Dr Irene G M van Valkengoed; i. g.vanvalkengoed@amc.nl

\section{ABSTRACT}

Objectives In South Asian populations, little is known about the effects of intensive interventions to reduce the risk of type 2 diabetes on health behaviour. We examined the effectiveness at 2 years of a culturally targeted lifestyle intervention on diet, physical activity and determinants of behaviour change among South Asians at risk for diabetes. Design Randomised controlled trial with de facto masking.

Setting Primary care.

Participants A total of 536 18- to 60-year-old South Asians at risk for diabetes (ie, with impaired glucose tolerance, impaired fasting glucose or relatively high insulin resistance) were randomised to the intervention $(n=283)$ or a control $(n=253)$ group. Data of 314 participants ( $n=165$ intervention, $n=149$ control) were analysed.

Interventions The culturally targeted intervention consisted of individual counselling using motivational interviewing (six to eight sessions in the first 6 months plus three to four booster sessions), a family session, cooking classes and a supervised physical activity programme. The control group received generic lifestyle advice.

Outcome measures We compared changes in physical activity, diet and social-cognitive underlying determinants between the two groups at 2-year follow-up with independent-sample t-tests, chi-square tests and Fisher's exact tests.

Results At the 2-year follow-up, participants in the intervention group were more moderately to vigorously active than at baseline, but compared with changes in the control group, the difference was not significant (change $\mathrm{min} /$ week 142.9 vs $0.5, \mathrm{p}=0.672$ ). Also, no significant difference was found between the two groups in changes on any of the components of the diet or the socialcognitive determinants of diet and physical activity. Conclusions The culturally targeted lifestyle intervention led to high drop-out and was not effective in promoting healthy behaviour among South Asians at risk for diabetes. Given the high a priori risk, we recommend to develop new
Strengths and limitations of this study

- The intensive intervention in this trial was culturally targeted, based on a needs assessment and formative research, to characteristics of South Asians living in the Netherlands.

- This study reports on physical activity, diet as well as the determinants of behaviour change, thus contributing to the yet limited knowledge about the effects of intensive interventions on behavioural measures among South Asians.

- Low participation and high drop-out from the trial may indicate poor acceptability of the intervention and may have led to a biased estimate of intervention effects.

- We assessed the intervention effects on health behaviours with self-reported measures, which may be influenced by various reporting biases.

strategies, preferably more acceptable, to promote healthy behaviour.

Trial registration NTR1499; Results. www.trialregister.nl/ trialreg/admin/rctview.asp?TC=1499

\section{BACKGROUND}

Diet and physical activity are key modifiable risk factors for type 2 diabetes mellitus (T2D), and interventions targeting these behaviours can help to prevent or postpone this disease. ${ }^{1-5}$ Efficacy trials have shown that, in high-risk individuals, the onset of T2D may be prevented or postponed through individual diet counselling and physical activity guidance through reduction in weight and waist circumference. ${ }^{2-5}$ Trials in a standard care setting aimed at promoting a healthy diet and physical activity have yielded similar, although more modest, results. ${ }^{6-8}$ 
South Asian migrants and their offspring (hereafter referred to as 'South Asians') living in high-income countries are, in particular, at high risk for T2D. ${ }^{9-13}$ Strategies targeting diet and physical activity have been implemented to reduce this increased risk among these populations. However, the trials evaluating intensive diet counselling and physical activity guidance in South Asian populations in the UK and in the Netherlands yielded only moderate results in terms of the reduction of weight and waist circumference. ${ }^{1415}$

One of the reasons for the moderate results could be that, in these trials, the interventions implemented do not lead to the intended changes in dietary behaviour and physical activity. However, little is known about the effects of intensive interventions on behavioural measures among South Asians. ${ }^{16}$ These measures include dietary behaviour and physical activity and social-cognitive determinants (such as self-efficacy) as a result of which changes in these behaviours occur. ${ }^{17-19}$

Therefore, the present study aims to analyse the effectiveness of an intervention among South Asians living in the Netherlands aimed at preventing T2D, with regard to changes in dietary habits, physical activity and the social-cognitive determinants of behaviour change.

Whereas our earlier study described the effects of this intervention on weight and other metabolic outcomes after one year, ${ }^{14}$ the effects on behavioural measures have not yet been investigated. In this intervention, motivational interviewing and tailored risk information were used to address social-cognitive factors underlying dietary behaviour and physical activity, including risk perception, attitudes, social support and self-efficacy. The intervention was based on a needs assessment and formative research and targeted to characteristics of South Asians Surinamese, who are the descendants of contract labourers who migrated to Surinam mostly from North India.

\section{METHODS}

\section{Study population}

All those included in the present investigation were participants of the DHIAAN study: this is a randomised controlled trial (No NTR1499) investigating the effectiveness of a culturally targeted intensive lifestyle intervention to prevent T2D and cardiovascular risk factors among South Asian Surinamese in primary care. ${ }^{20}$ The term South Asian Surinamese refers to people of South Asian ancestral origin and their offspring who migrated to the Netherlands via Suriname. The South Asian Surinamese are descendants of the labourers from North India (Uttar Pradesh, Uttaranchal and West Bihar) who were indentured between 1873 and 1917. The two large migration waves of South Asian Surinamese to the Netherlands were caused mainly by the political situation in Suriname. The first wave took place at the time of the independence of Suriname in 1975; and the second wave (at the time of Desi Bouterse's coup), in February 1980. ${ }^{21}$
Details of the DHIAAN study, including changes to the original protocol and the process of adapting the lifestyle intervention for the social-cultural and social-cognitive determinants of South Asian Surinamese, are already published. ${ }^{20}{ }^{22}$ In brief, 2307 South Asian Surinamese (aged 18-60 years) living in The Hague (the Netherlands) were screened via general practices between 18 May 2009 and 11 October 2010 (figure 1). To achieve a high response rate, a culturally targeted intensive recruitment strategy was used that was proven feasible in the pilot of the DHIAAN study. ${ }^{20}$ General practitioners (GPs) sent each potential participant an invitation, together with a reply card that could be returned if further contact was not wanted. Invitees who did not respond received a written reminder and were also contacted by telephone.

All potential participants were requested to fill out a brief questionnaire, undergo a physical examination and provide a fasting blood sample. The 968 participants who were invited and screened between 18 May 2009 and 18 April 2010 also took an oral glucose tolerance test (75 g). Thereafter, the oral glucose tolerance test was discontinued for practical reasons. Due to the shorter duration of a screening with a single measurement, a greater number of people could be screened within the extended recruitment period. ${ }^{20}$

\section{Inclusion in the trial}

Screened participants with impaired fasting glucose (fasting glucose of $5.6-6.9 \mathrm{mmoL} / \mathrm{L}$ ), impaired glucose tolerance (2-hour postload glucose of 7.8-11.0 mmoL/L), a glycated haemoglobin (HbA1c) level of $\geq 42 \mathrm{mmoL} /$ mol and/or a value of $\geq 2.39$ for the homeostasis model assessment-insulin resistance (HOMA-IR) were invited to participate in the trial $^{20}$ (figure 1).

Excluded was anyone who was already involved in a lifestyle programme, was pregnant, had a chronic disease that made participation in the intervention impossible and/or used drugs that interfered with plasma glucose levels. Also excluded were participants with newly diagnosed T2D (ie, a fasting glucose $\geq 7.0 \mathrm{mmoL} / \mathrm{L}$, a 2-hour postload glucose $\geq 11.0 \mathrm{mmoL} / \mathrm{L}$ or an $\mathrm{HbAlc}$ level $\geq 48 \mathrm{mmoL} / \mathrm{mol}$ ); these persons were referred to regular clinical care.

As described previously in more detail, ${ }^{14} 20536$ people were randomly assigned to either the intervention or the control group using a computer-generated randomisation list (simple randomisation). Family or household members, defined by postal code and house number, were assigned to the same group. Participants were informed about the procedures for the arm of the trial that they were assigned to; the masking (de facto masking) of the two groups was maintained throughout the trial.

The study was approved by the institutional review board of the Academic Medical Centre, Amsterdam. All participants provided both oral and written informed consent. 


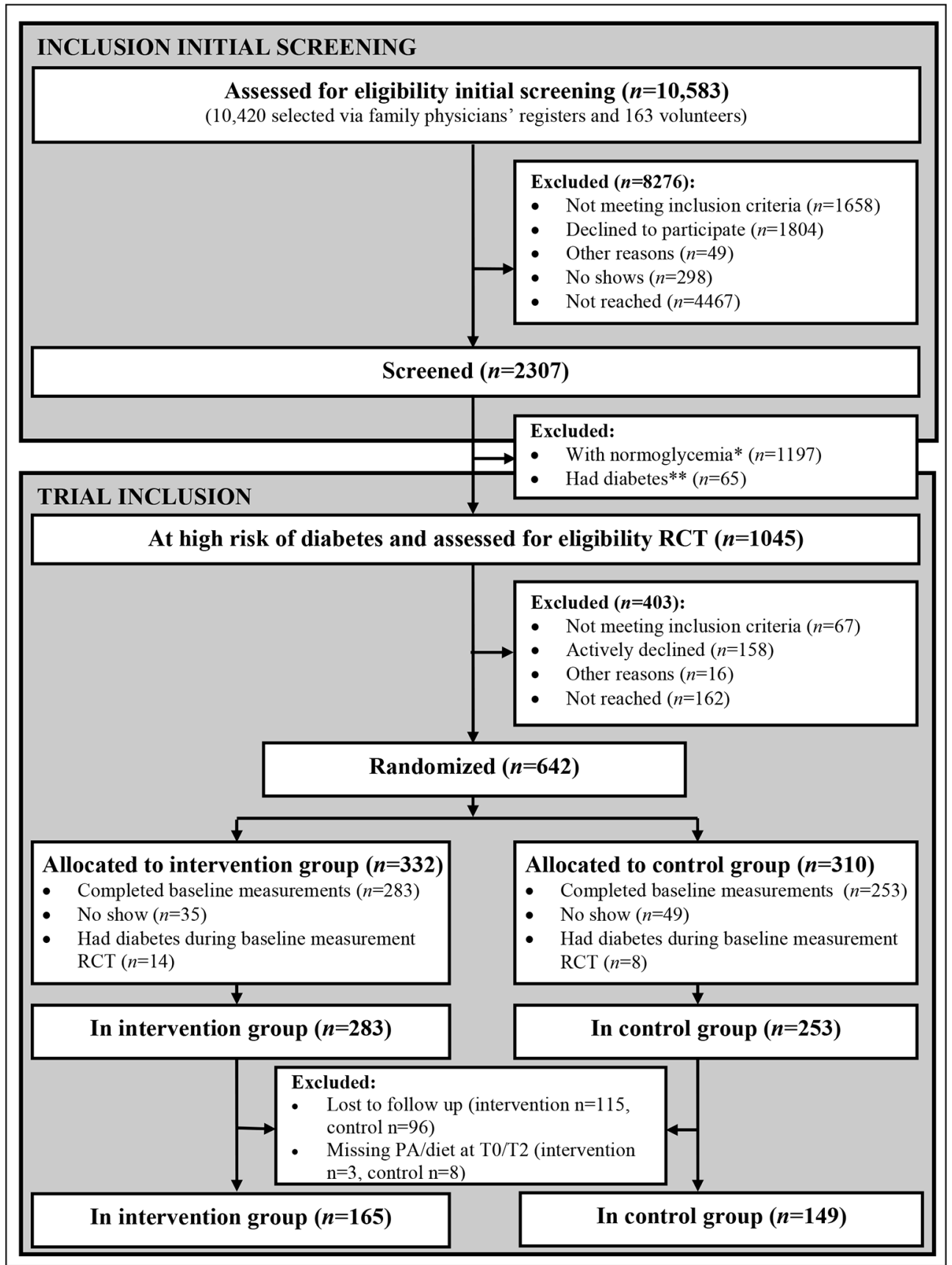

Figure 1 Flow chart of inclusion of the study participants. *A fasting glucose of $5.5 \mathrm{mmoL} / \mathrm{L}$ or lower, a 2-hour postload glucose of $7.7 \mathrm{mmoL} / \mathrm{L}$ or lower, a glycated haemoglobin level of $5.9 \%$ or lower and a value of 2.38 or lower for the homeostasis model assessment of estimated insulin resistance. ${ }^{* \star} \mathrm{A}$ fasting glucose of $7.0 \mathrm{mmoL} / \mathrm{L}$ or more and/or a 2-hour postload glucose of $11.1 \mathrm{mmoL} / \mathrm{L}$ or more. PA, physical activity; RCT, randomised controlled trial; T0, baseline measurement; T2, measurement at 2-year follow-up.

\section{Intervention group}

All participants in the intervention group were offered a culturally targeted lifestyle intervention. ${ }^{22}$ The design of this intervention was in line with the design of the proven efficacious intervention used in the Study on Lifestyle Intervention and Impaired Glucose Tolerance Maastricht (SLIM), which aimed to evaluate the effect of that intervention on glucose tolerance in a European Dutch population. ${ }^{23}$ In line with that and other interventions in this field, the theoretical starting point of our intervention was the notion that motivation for behaviour change is driven by personal determinants, including attitudes, social influences and self-efficacy. In our intervention, we used the technique of motivational interviewing to address these personal determinants. ${ }^{22}$ In addition, the technique could address other factors (eg, stress) if relevant for the individual's behaviour. We also involved the family members in the intervention to strengthen the participants to cope with social pressure to eat sweet and fat products (see below). 
To address the sociocultural influences that affect these personal determinants, we culturally adapted the intervention as used in the SLIM study to the South Asian Surinamese population. We have described the theoretical framework underlying the intervention and adaptations in detail elsewhere. ${ }^{22}$ In short, the aim was to enhance the cultural sensitivity of the intervention, as this is likely to promote the effectiveness of interventions among specific ethnic populations. ${ }^{24}$ We based our definition of cultural sensitivity on that of Resnicow: 'the extent to which ethnic/cultural characteristics, experiences, norms, values, behavioural patterns and beliefs of a target population as well as relevant historical, environmental and social forces are incorporated in the design, delivery and evaluation of targeted health promotion interventions'. ${ }^{25}$ Cultural adaptations are divided into two major dimensions: surface structure, which involves matching interventions materials and message to the observable behaviour characteristics that are shared by the target population, and deep structure adaptations, which target the social or cultural values underlying these behaviours. We used both type of adaptations, for example, a study logo based on the design of the Surinamese flag and propositions on culturally held ideas regarding diabetes mellitus for the family session, respectively, to make the intervention attractive, appropriate and ultimately more potentially effective in the present study population. ${ }^{22}$ These adaptations were based on formative research, including literature review, focus groups and the experiences in a pilot study. ${ }^{22}$

The intervention was designed to be carried out by dieticians within their usual practice setting. The aim was to meet current national guidelines for diet and physical activity. ${ }^{26}{ }^{27}$ In the first 6 months, dieticians used motivational interviewing during six to eight individual lifestyle counselling sessions, followed by three to four booster sessions over the following 18 months. The dieticians were trained in motivational interviewing, in which previous successes, skills and strengths of the client were highlighted to support self-efficacy. ${ }^{28}$ All dieticians were also familiar with the South Asian culture and dietary habits; three had South Asian roots themselves, and the other three had experience working within the South Asian community. On the basis of the aforementioned formative research, we identified four goals that seem to be particularly important for promoting the effectiveness of the intervention and for addressing the barriers and motivating factors that appeared to be relevant in this South Asian population. These were as follows: (1) generating appropriate risk perception and conviction that diabetes can be prevented or at least postponed, (2) generating a positive attitude toward a healthy lifestyle, (3) mobilising social support by involving participants' families in the intervention and (4) creating the conviction that healthy eating can also be tasty. ${ }^{22}$

In line with these goals, dieticians as well as the written materials paid specific attention to the issues of risk perception (eg, by stressing the modifiability of risk factors for T2D) and positive attitude toward diet and physical activity (eg, by giving suggestions for healthy eating based on traditional foods). In addition, dieticians offered a family session at the participant's home, with the aim to engage the family in supporting the individual participant in achieving dietary goals. Finally, participants were offered two group-based cooking classes to learn skills for adjusting traditional dishes to meet nutritional guidelines, thereby also increasing their self-efficacy.

We also offered a 20-week physical activity programme to all participants in the intervention group. This 'exercise on prescription' programme is described elsewhere. ${ }^{29-31}$ Trained coaches monitored participation in the programme.

\section{Control group}

Participants in the control group were invited to join two group sessions led by student dieticians (at baseline and after 6 months). The sessions provided generic information about T2D and discussed current guidelines for diet and physical activity. These participants received two leaflets (at 3 and 9 months) with simple, generic lifestyle advice. The group sessions and leaflets were not targeted to characteristics of the target population.

\section{Data collection}

Trial visits were planned for both groups at baseline and after 1 and 2 years. ${ }^{20}$ The invitation procedures for these visits were similar to the intensive procedures used during the screening. Participants who did not respond to the invitation for the follow-up visit were contacted by telephone and received a written reminder. In addition to written confirmation of their appointment, all participants received a text message reminder the day before their appointment.

During the visit, a trained interviewer conducted a face-to-face interview with each participant in Dutch or, optionally, in Sarnami (Surinamese dialect based on North Indian dialects). At baseline, two participants in the trial asked to be interviewed in Sarnami. Trained research staff used a standardised protocol for the physical examinations. They measured weight on a mechanical scale (Seca 761, Hamburg, Germany) to the nearest $500 \mathrm{~g}$, and height was measured to the nearest $0.01 \mathrm{~m}$. The anthropometric measurements were obtained twice, and the means were used for analysis.

During all visits, all participants provided a fasting blood sample and were offered an oral glucose tolerance test. Measurements of fasting plasma glucose and 2-hour postload glucose (oral glucose tolerance test, $75 \mathrm{~g}$; hexokinase, Roche Diagnostics), HbAlc (high-performance liquid chromatography) and insulin (immunoassay, sandwich principle, Roche Diagnostics) were carried out according to a standardised protocol at the SHL Group (laboratory), Etten-Leur (the Netherlands). The HOMA-IR was calculated as glucose $(\mathrm{mmol} / \mathrm{L})$ multiplied by fasting insulin $(\mathrm{mU} / \mathrm{L})$ divided by $22.5{ }^{32}$ 
Table 1 Categories used for meeting the dietary guidelines

Meeting the guideline*

\begin{tabular}{|c|c|}
\hline Fruit intake & 2 pieces of fruit/day \\
\hline Vegetable intake & $200 \mathrm{~g}$ vegetables/day \\
\hline Whole wheat intake & $\begin{array}{l}\text { Almost exclusively whole wheat } \\
\text { products }\end{array}$ \\
\hline Regular eating pattern & 3 meals/day at a regular time \\
\hline Rice intake & Almost exclusively brown rice \\
\hline
\end{tabular}

*Derived from the current national guidelines for diet, ${ }^{26}$ with the exception of rice for which no guideline has been established.

Data on participation were recorded by dieticians and obtained from the process data collected from participants during the first year. ${ }^{20}$

\section{Measurements and definitions}

Physical activity, diet and social-cognitive determinants of behaviour change were noted during the trial visits. ${ }^{23} 33$ Physical activity was assessed with the Short Questionnaire to Assess Health-Enhancing Physical Activity, supplemented with culturally specific activities. ${ }^{34}$ Three measures were defined as follows: (1) any versus no moderate-to-vigorous activity, (2) the total moderate-to-vigorous activity expressed in $\mathrm{min} /$ week and (3) the total activity expressed in $\mathrm{min} /$ week.

Dietary intake was determined using questions based on the national guidelines for a healthy diet, supplemented with questions on group-specific dietary behaviours of the South Asian population ${ }^{22} 26$ (see online supplement 1). Fruit, vegetables, rice and whole wheat intake was assessed with multi-item questions (with 3, 2, 2 and 11 items, respectively) to determine the quantity and frequency. Moreover, two single-item questions addressed the regularity of the meals. These aspects of the diet were dichotomised into meeting versus not meeting the guideline (table 1).

\section{Social-cognitive determinants of behaviour change}

Risk perception consisted of measures of perceived susceptibility and two components of Leventhal's common sense model of representations of illness and self-regulation, ${ }^{36}$ that is, causal beliefs and perceived controllability by physical activity. Causal beliefs were measured with 12 statements about the perceived influence of certain behaviours or characteristics on the onset of diabetes, on a 3-point Likert scale. The statements concerned (1) general lifestyle beliefs related to seven general risk factors for diabetes, (2) three group-specific lifestyle beliefs (consumption of masala and large amounts of white rice and sugar) derived from our focus group discussions and (3) two heredity beliefs (eg, family history of diabetes and being a South Asian). ${ }^{22} 37$ The internal consistency of items was estimated with Cronbach's alpha $(\alpha)$, and an $\alpha$ above 0.6 was considered to be moderate and above 0.8 good. The general lifestyle beliefs related to overweight, unhealthy food, insufficient exercise, hypertension, age and smoking were combined into a single factor based on the results of internal consistency analysis $(n=6, \alpha=0.63$; a score of $\geq 4$ indicating 'perceiving general lifestyle as a cause of type 2 diabetes mellitus'). Perceived controllability with physical activity was measured by a single item on a 5-point Likert scale. Perceived susceptibility was measured with a three-item perceived susceptibility score, on a 5-point Likert scale $(\mathrm{n}=3, \alpha=0.63) .^{38}$

Internal consistency analysis resulted in three factors for attitudes toward physical activity and diet: direct (enjoyment and importance; $n=4, \alpha=0.64$ ) and indirect attitude toward physical activity (possible consequences of increasing physical activity; $n=7, \alpha=0.67$ ) and the attitude toward conventional healthy dietary behaviours (enjoyment and importance of a regular eating pattern and breakfast, fruit, vegetable, whole wheat intake; $n=10$, $\alpha=0.84$ ). We also measured the attitudes (enjoyment and importance) toward two group-specific healthy dietary behaviours (replacing white rice with brown rice and refusing snacks at parties).

Two factors were formed for social support: perceived social support for physical activity from other family members and close relatives $(n=2, \alpha=0.68)$ and perceived social support for the conventional healthy dietary behaviours $(n=5, \alpha=0.94)$. We also measured the perceived social support for physical activity from the spouse and the perceived social support for two group-specific healthy dietary behaviours (replacing white rice with brown rice and refusing snacks at parties).

Self-efficacy was reflected in two combined factors: perceived self-efficacy for physical activity $(n=5$, $\alpha=0.73$ ) and perceived self-efficacy for the conventional healthy dietary behaviours $(n=5, \alpha=0.66)$. Moreover, we measured self-efficacy expectations for two group-specific healthy dietary behaviours (replacing white rice with brown rice and refusing snacks at parties).

The stages of change toward diet and physical activity were classified as being motivated or not motivated to change one's diet according to the Dutch guidelines and physical activity within 6 months. The stage of change toward diet was measured for each specific dietary behaviour. One factor was formed for stage of change toward the conventional healthy dietary behaviours $(n=5$, $\alpha=0.73$ ).

Because of the skewness of the variables, we dichotomised all resulting variables, for example, perceiving versus not perceiving having a family history of diabetes as cause. In addition, as the group-specific items (eg, refusing snacks at parties) did not load on the aforementioned scales, we decided to include these in the analysis as single items.

\section{Other factors}

Age and gender were determined from the GPs' registries. Country of birth, duration of residence, low education level (primary education or less) and having paid work were measured at the initial screening. Low family 
income ( $\leq € 998$ net/month) was determined at baseline. A family history of diabetes was defined as having a firstor second-degree family member with diabetes. Body mass index (BMI) was calculated as weight $(\mathrm{kg}) /$ height $(\mathrm{m})^{2}$.

\section{Statistical analysis}

In the current analysis, we included all those who participated in both the baseline measurement and measurement at 2-year follow-up and excluded anyone without data on physical activity or diet at baseline and/ or at 2-year follow-up (figure 1). This means that 314 participants remained for the present analysis: 165 in the intervention group with a mean follow-up time of 22.1 (95\% CI 21.0 to 23.8) months and 149 in the control group with a mean follow-up time of 22.1 (95\% CI 21.3 to 23.2) months.

We described the baseline characteristics of the remaining participants in both groups. Continuous variables were described using means (95\%CIs). Continuous variables that were not normally distributed, based on visual inspection, skewness and kurtosis values, were described with a median and IQR. Baseline differences in continuous variables between the intervention and control group were checked using independent-sample t-tests and, where relevant, Mann-Whitney U tests. Categorical variables were described by reporting the $n$ (percentage) with a certain characteristic. Group differences were tested with chi-square tests.

In addition, for those in the intervention group, their participation in elements of the intervention was described. We calculated the percentage who participated in the intake for the individual lifestyle counselling, and of this group, the percentage who attended at least one more session after the intake. We also report the median (IQR) number of sessions attended (in addition to the initial intake visit) within this group. Finally, we determined the percentage participating in cooking classes, family sessions and/or the supervised exercise programme.

Changes in physical activity, diet and the social-cognitive determinants of behaviour change are also described. For the continuous measures, the change was determined between baseline and 1- and 2-year follow-up, respectively. As the changes appeared normally distributed (based on visual inspection and the skewness and kurtosis values), we report the mean changes in the intervention and control groups. For the categorical measures, we determined the percentage of participants with a positive change (eg, those who changed from non-adherent to adherent to the guideline for fruit intake) or a negative change (eg, those who changed from a regular to an irregular meal pattern) at 1- and 2-year follow-ups. The remaining participants had not changed their behaviour for that specific measure. Except for the belief that masala intake is a possible cause of diabetes and the attitude toward refusing snacks at parties, positive changes were expected to positively influence lifestyle behaviour and health. Independent-sample t-tests were used to compare the mean changes between the intervention and control groups in continuous measures. Chi-square tests were used to compare the percentage positive and negative changes between the two groups. Where expected counts per cell were low, we merged the 'negative change' and 'unchanged' categories and compared the percentage 'positive change' across groups with a Fisher's exact test. As the present analysis focuses on the effects 2 years postbaseline, only the full $\mathrm{p}$ values for the differences at 2 years are reported.

In the present study, we did not consider multiple imputations or more complex modelling of patterns of missingness. This decision was based on a comparison of the baseline characteristics between participants with and those without a measurement at 2-year follow-up (see online supplement 2). Apart from being younger and having a higher HOMA-IR, those who participated in the measurement at 2-year follow-up had baseline characteristics similar to those who dropped out. We used logistic regression to examine differences in drop-out across groups. Drop-out was similar in both groups (age and sex adjusted OR 1.02 (95\% CI 0.72 to 1.45$)$ ), and these differences did not vary by age or gender ( $>0.05$ for the interaction terms). In addition, we previously analysed different patterns of missingness in relation to the reported total physical activity, meal pattern and whole wheat consumption, using a pattern mixture model in the total study population, and found no significant evidence for an effect of missingness on our outcomes (data not shown).

In the current paper, we did not perform multilevel analysis with the data on dieticians. In line with previous analyses of the DHIAAN data, ${ }^{1433}$ no evidence was found for dependencies between participants registered with the same dietician (data not shown). We analysed this with two-level regression models (individual and dietician) with a random intercept at the level of the dietician. Furthermore, as only 29 people with family members in the study had follow-up data available (intervention $n=18$, control $n=11$ ), no multilevel analysis was performed on family data. Analysis of reported total physical activity, meal pattern and whole wheat consumption after exclusion of all people with family members in the study showed similar results to the analysis in the full population (data not shown).

The SPSS 19.0 (SPSS, Chicago, Illinois, USA) and R2.15.3 (R Foundation for Statistical Computing, 2009) were used for the analyses. A p-value $<0.05$ was considered to be statistically significant.

\section{RESULTS}

\section{Baseline characteristics}

At baseline, both groups were similar in terms of demographic characteristics and physical activity (table 2). Most of the participants reported to be moderately to vigorously active: $82 \%$ of the intervention group and 
Table 2 Baseline characteristics of participants with a measurement of physical activity and diet at baseline and at 2-year follow-up measurement

\begin{tabular}{|c|c|c|c|}
\hline & & $\begin{array}{l}\text { Intervention group, } \\
\mathrm{n}=165\end{array}$ & Control group, n=149 \\
\hline \multirow[t]{8}{*}{ Sociodemographic } & Male & $75(45.5)$ & $77(52.0)$ \\
\hline & Mean age (years) & $44.9(43.5-46.5)$ & $44.7(43.1-46.4)$ \\
\hline & Low education & 16 (10.1) & $20(13.8)$ \\
\hline & Paid work & $115(70.6)$ & $104(70.3)$ \\
\hline & Family income $\leq € 998$ net/month & $18(2.3)$ & $14(10.0)^{\star}$ \\
\hline & Country of birth (Netherlands) & $14(8.5)$ & $14(9.5)$ \\
\hline & Mean duration of residence (years) & $28.8(28.2-30.4)$ & $27.9(26.4-29.4)$ \\
\hline & Family history of diabetes & $124(77.5)$ & $103(71.5)$ \\
\hline \multirow[t]{5}{*}{ Metabolic } & Mean body mass index & $27.7(27.1-28.3)$ & $27.2(26.6-27.8)$ \\
\hline & Mean fasting plasma glucose & $5.3(5.2-5.4)$ & $5.3(5.3-5.4)$ \\
\hline & Mean 2-hour postload glucose & $6.1(5.8-6.3)$ & $6.0(5.7-6.2)$ \\
\hline & Mean glycated haemoglobin & $5.7(5.6-5.8)$ & $5.7(5.6-5.7)$ \\
\hline & Median HOMA-IR & $3.0(2.2-4.1)$ & $2.8(2.1-3.9)$ \\
\hline \multirow[t]{3}{*}{ Physical activity } & Any moderate-to-vigorous activity & $135(81.8)$ & $118(79.2)$ \\
\hline & $\begin{array}{l}\text { Mean moderate-to-vigorous activity (min/ } \\
\text { week) }\end{array}$ & $628.0(504.1-751.9)$ & $665.6(523.2-807.9)$ \\
\hline & Mean total activity (min/week) & 2698.8 (2534.2-2863.5) & $2451.3(2262.7-2640.0)$ \\
\hline \multirow[t]{5}{*}{ Dietary intake $\dagger$} & Fruit: 2 pieces /day (\%) & $71(43.3)$ & 55 (36.9) \\
\hline & Vegetables: 200 g/day (\%) & $112(67.9)$ & $48(56.4) \ddagger$ \\
\hline & Whole wheat: almost exclusively (\%) & $11(6.7)$ & $11(7.4)$ \\
\hline & $\begin{array}{l}\text { Meal pattern: } 3 \text { meals/day at a regular times } \\
\text { (\%) }\end{array}$ & $94(57.3)$ & $82(55.4)$ \\
\hline & Brown rice: almost exclusively (\%) & $21(12.8)$ & $11(7.4)$ \\
\hline \multirow[t]{9}{*}{ Risk perception } & Causal beliefs & & \\
\hline & $\begin{array}{l}\text { Perceiving } 6 \text { general risk factors as cause } \\
(\%) \ddagger\end{array}$ & $110(66.7)$ & $103(69.1)$ \\
\hline & $\begin{array}{l}\text { Perceiving consuming a lot of sugar as } \\
\text { cause }(\%)\end{array}$ & $113(68.5)$ & $105(70.5)$ \\
\hline & $\begin{array}{l}\text { Perceiving consuming a lot of white rice as } \\
\text { cause }(\%)\end{array}$ & $95(57.6)$ & $86(57.7)$ \\
\hline & Perceiving consuming masala as cause§ & $49(29.9)$ & $48(32.4)$ \\
\hline & Perceiving being a South Asian as cause & $122(73.9)$ & $104(69.8)$ \\
\hline & $\begin{array}{l}\text { Perceiving having a family history of } \mathrm{T} 2 \mathrm{D} \text { as } \\
\text { cause }\end{array}$ & $150(90.9)$ & $134(89.9)$ \\
\hline & High susceptibility & $63(38.2)$ & $71(47.7)$ \\
\hline & High controllability belief by physical activity & $146(88.5)$ & $132(88.6)$ \\
\hline \multirow[t]{9}{*}{ Positive attitude toward } & Physical activity & & \\
\hline & Direct & $160(97.0)$ & $143(96.0)$ \\
\hline & Indirect & $161(97.6)$ & $142(95.3)$ \\
\hline & Diet & & \\
\hline & In general & $161(98.2)$ & $148(99.3)$ \\
\hline & Importance brown rice & $76(46.1)$ & $62(41.6)$ \\
\hline & Importance snacks & $51(31.5)$ & $39(26.4)$ \\
\hline & Enjoyment brown rice & $43(27.0)$ & $30(20.5)$ \\
\hline & Enjoyment snacks & $93(58.1)$ & $67(45.6)^{\ddagger}$ \\
\hline
\end{tabular}


Table 2 Continued

\section{Intervention group,}

$n=165$

Control group, $n=149$

\begin{tabular}{|c|c|c|c|}
\hline \multirow[t]{3}{*}{ Perceiving social support } & \multicolumn{3}{|l|}{ Physical activity } \\
\hline & Partner & $71(43.0)$ & $66(44.3)$ \\
\hline & Others & $103(62.4)$ & 99 (66.4) \\
\hline & \multicolumn{3}{|l|}{ Diet } \\
\hline & In general & $98(59.8)$ & $85(57.0)$ \\
\hline & Brown rice & $44(26.8)$ & $41(27.5)$ \\
\hline & Refusing snacks & $48(29.3)$ & $45(30.2)$ \\
\hline \multirow[t]{5}{*}{ Perceiving self-efficacy } & Physical activity & $109(66.1)$ & $103(69.1)$ \\
\hline & Diet & & \\
\hline & In general & $151(91.5)$ & $136(91.3)$ \\
\hline & Brown rice & $56(33.9)$ & $38(25.5)$ \\
\hline & Refusing snacks & $98(60.5)$ & $101(69.7)$ \\
\hline \multirow{4}{*}{$\begin{array}{l}\text { Stage of change- } \\
\text { motivated to change }\end{array}$} & Physical activity within 6 months & 99 (59.3) & $105(69.5)$ \\
\hline & \multicolumn{3}{|l|}{ Diet within 6 months } \\
\hline & In general & $153(92.7)$ & $135(90.6)$ \\
\hline & Brown rice & $82(49.7)$ & 59 (39.6) \\
\hline
\end{tabular}

Data are presented as means $(95 \% \mathrm{Cl})$, median (25th-75th percentile) or $\mathrm{n}$ (percentage).

*Estimated net income was not reported by 54 (17.0\%) of participants. Differences between groups were, therefore, not assessed.

†Derived from the national guidelines for diet $\left({ }^{30}\right)$, with the exception of rice for which no guideline has been established.

$\ddagger$ Significant difference between the groups at baseline (TO).

$\S$ Six common risk factors: overweight, too little exercise, unhealthy diet, age $\geq 35$ years, smoking and hypertension.

HOMA-IR, Homeostasis Model of Assessment-Insulin Resistance; T2D, type 2 diabetes mellitus.

$79 \%$ of the control group. Moreover, at baseline, similar proportions in both groups met the guidelines for fruit, whole wheat intake, a regular meal pattern and use of brown rice. However, vegetable intake differed between the groups: $68 \%$ of the intervention group ate $200 \mathrm{~g}$ of vegetables/day compared with $56 \%$ of the control group. At baseline, the social-cognitive determinants (with the exception of enjoyment of snacks) were also similar in both groups. The observed percentage of people with a positive response varied largely between the determinants. For example, $\geq 90 \%$ of both groups had a positive attitude toward physical activity and a healthy diet, whereas $\leq 50 \%$ of the population reported to experience social support from their partner regarding healthy behaviour.

\section{Participation in the intervention}

In the intervention group, $81.8 \%$ of the respondents participated in the intake for the individual lifestyle counselling sessions. Of this latter group, $94.8 \%$ attended at least one additional session, with a median number of eight sessions (IQR 4-9) per person. Moreover, 14.4\% participated in a supplemental family session; $12.7 \%$, in the cooking classes; and $26.3 \%$, in the supervised exercise sessions.

\section{Effect of the intervention on physical activity and diet}

Participants in the intervention group were more moderately to vigorously active at 2-year follow-up than at baseline, but compared with the change in the control groups, the difference was not significant (table 3). In addition, while more participants in the intervention group than in the control group met the guidelines for several dietary behaviours (eg, whole wheat intake, eating brown rice and fruit) at 2-year follow-up, none of these changes significantly differed between the groups (table 3).

Remarkably, a substantial percentage of people who were adherent to a specific guideline at baseline were no longer adherent 1 or 2 years later ('negative' change). For most behaviours, this percentage is almost as high as the percentage 'positive' change.

\section{Effect of the intervention on social-cognitive determinants of behaviour change}

At 2-year follow-up, no significant difference was found between the two groups in any of the social-cognitive determinants of behaviour change (table 4). A positive change was observed in several of the social-cognitive determinants of behaviour change among part of the intervention group, and similar changes were observed in the control group. For instance, $22.4 \%$ of those in the intervention group who did not perceive themselves as susceptible at baseline perceived themselves as susceptible to the onset of diabetes after 2 years; in the control group, this figure was $21.5 \%$ ( $\mathrm{p}=0.941$ for the difference between 
Table 3 Effectiveness of intervention on physical activity and dietary behaviour among South Asians at risk for diabetes

Changes in intervention group, $\mathrm{n}=165$

Changes in control group, $\mathrm{n}=149$

p Value

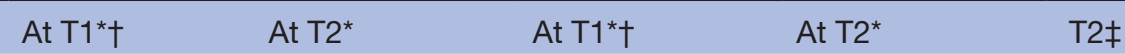

Physical Any moderate-to-vigorous

activity activity

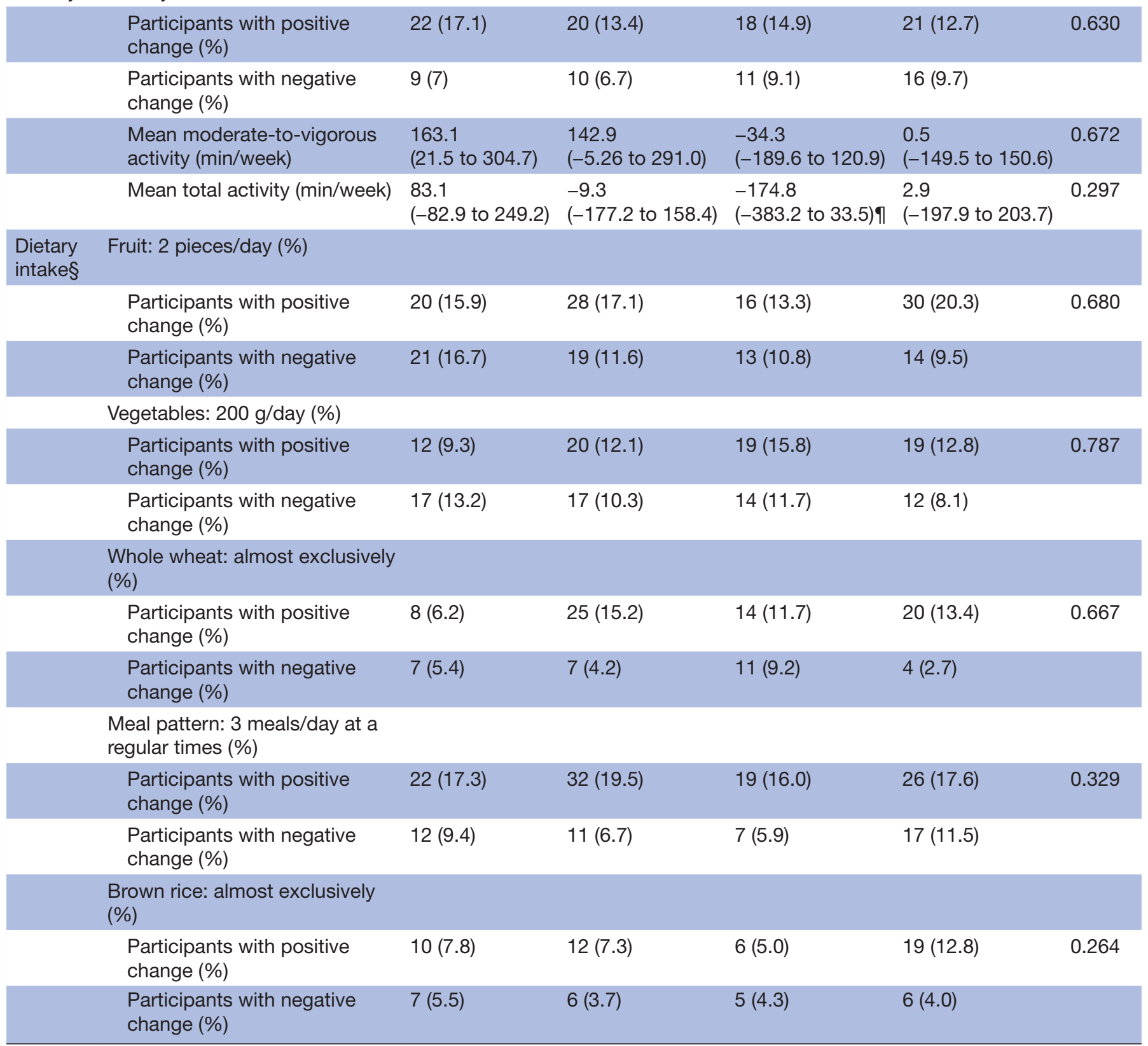

${ }^{*}$ Changes from T0 to T1 and T0 to T2 are described as number (percentage of total population) with a positive change (eg, from non-adherent to adherent to the guideline for fruit intake) or a negative change (eg, from a regular to an irregular meal pattern) at 1 and 2 years. The remaining participants had not changed their dietary intake or physical activity. For continuous measures, a mean change (95\% $\mathrm{Cl})$ is given. †Of the 314 participants with a measurement at baseline and at 2-year follow-up, 279 also attended the measurement at 1-year follow-up (148 in the intervention group and 131 in the control group).

$\neq \mathrm{p}$ Value for the intention-to-treat analysis of the difference in changes from T0 to T2 between the two groups.

$\S$ Derived from the national guidelines for $\operatorname{diet}\left({ }^{30}\right)$, with the exception of rice for which no guideline has been established.

П $\mathrm{p}=0.036$.

T0, baseline measurement; T1, measurement after 1 year; T2, measurement after 2 years. 
Table 4 Effectiveness of intervention on determinants of behaviour among South Asians at risk for diabetes $(n=314)$

\begin{tabular}{|c|c|c|}
\hline $\begin{array}{l}\text { Changes in } \\
\text { intervention group, } \\
\mathrm{n}=165\end{array}$ & $\begin{array}{l}\text { Changes in control } \\
\text { group, } n=149\end{array}$ & $p$ Value \\
\hline At T1*十 & At T1*十 & T2‡ \\
\hline
\end{tabular}

Risk perception Causal beliefs

Perceiving six general risk factors as cause $(\%) \S$

$\begin{array}{llllll}\text { Participants with positive change (\%) } & 20(15.5) & 32(19.4) & 24(19.8) & 33(22.1) & 0.818 \\ \text { Participants with negative change (\%) } & 16(12.4) & 16(9.7) & 12(9.9) & 13(8.7) & \end{array}$

Perceiving consuming a lot of sugar as cause (\%)

$\begin{array}{llllll}\text { Participants with positive change (\%) } & 18(14.1) & 21(12.7) & 16(13.2) & 18(12.1) & 0.458 \\ \text { Participants with negative change (\%) } & 32(25.0) & 34(20.6) & 16(13.2) & 23(15.4) & \end{array}$

Perceiving consuming a lot of white rice as cause

(\%)

\begin{tabular}{|c|c|c|c|c|c|c|}
\hline & Participants with positive change (\%) & $25(19.4)$ & $35(21.2)$ & $33(27.3)$ & $39(26.2)$ & 0.552 \\
\hline & Participants with negative change (\%) & $18(14.0)$ & $21(12.7)$ & $10(8.3)$ & $16(10.7)$ & \\
\hline & \multicolumn{6}{|l|}{ Perceiving consuming masala as cause $\|$} \\
\hline & Participants with positive change (\%) & $11(8.7)$ & $22(13.4)$ & $17(14.0)$ & $19(12.8)$ & 0.569 \\
\hline & Participants with negative change (\%) & $27(21.3)$ & $29(17.7)$ & $17(14.0)$ & $20(13.5)$ & \\
\hline & \multicolumn{6}{|l|}{ Perceiving being a South Asian as cause } \\
\hline & Participants with positive change (\%) & $19(14.7)$ & $24(14.5)$ & $18(14.9)$ & $30(20.1)$ & 0.395 \\
\hline & Participants with negative change (\%) & $13(10.1)$ & $15(9.1)$ & $12(9.9)$ & $11(7.4)$ & \\
\hline & \multicolumn{6}{|c|}{ Perceiving having a family history of $\mathrm{T} 2 \mathrm{D}$ as cause } \\
\hline & Participants with positive change (\%) & $8(6.2)$ & $12(7.3)$ & $10(8.3)$ & $12(8.1)$ & 0.798 \\
\hline & Participants with negative change (\%) & $9(7.0)$ & $13(7.9)$ & $4(3.3)$ & $9(6.0)$ & \\
\hline & \multicolumn{6}{|l|}{ High susceptibility } \\
\hline & Participants with positive change (\%) & $24(18.6)$ & $37(22.4)$ & $28(23.1)$ & $32(21.5)$ & 0.941 \\
\hline & Participants with negative change (\%) & $11(8.5)$ & $17(10.3)$ & $17(14.0)$ & $17(11.4)$ & \\
\hline & \multicolumn{6}{|l|}{ High controllability belief by physical activity } \\
\hline & Participants with positive change (\%) & $5(3.9)$ & $15(9.1)$ & $8(6.6)$ & $12(8.1)$ & 0.619 \\
\hline & Participants with negative change (\%) & $7(5.5)$ & $9(5.5)$ & $8(6.6)$ & $5(3.4)$ & \\
\hline \multirow{16}{*}{$\begin{array}{l}\text { Positive attitude } \\
\text { toward }\end{array}$} & Physical activity & & & & & \\
\hline & \multicolumn{6}{|l|}{ Direct } \\
\hline & Participants with positive change (\%) & $3(2.4)$ & $4(2.4)$ & $3(2.5)$ & $4(2.7)$ & $1.0^{\star *}$ \\
\hline & Participants with negative change (\%) & $2(1.6)$ & $0(0.0)$ & $1(0.8)$ & $0(0.0)$ & \\
\hline & \multicolumn{6}{|l|}{ Indirect } \\
\hline & Participants with positive change (\%) & $4(3.1)$ & $4(2.4)$ & $3(2.5)$ & $5(3.4)$ & $0.740^{\star \star}$ \\
\hline & Participants with negative change (\%) & $3(2.3)$ & $6(3.6)$ & $2(1.7)$ & $1(0.7)$ & \\
\hline & \multicolumn{6}{|l|}{ Diet } \\
\hline & \multicolumn{6}{|l|}{ In general } \\
\hline & Participants with positive change (\%) & $2(1.6)$ & $2(1.2)$ & $1(0.8)$ & $1(0.7)$ & $1.0^{* *}$ \\
\hline & Participants with negative change (\%) & $2(1.6)$ & $1(0.6)$ & $2(1.7)$ & $1(0.7)$ & \\
\hline & \multicolumn{6}{|l|}{ Importance brown rice } \\
\hline & Participants with positive change (\%) & $34(26.4)$ & $40(24.2)$ & $30(24.8)$ & $39(26.2)$ & 0.739 \\
\hline & Participants with negative change (\%) & $13(10.1)$ & $16(9.7)$ & $16(13.2)$ & $11(7.4)$ & \\
\hline & \multicolumn{6}{|l|}{ Importance snacks§ } \\
\hline & Participants with positive change (\%) & $18(14.5)$ & $20(12.3)$ & $20(16.8)$ & $11(7.4)$ & 0.298 \\
\hline
\end{tabular}


Table 4 Continued

\begin{tabular}{|c|c|c|c|c|c|c|}
\hline & & \multicolumn{2}{|c|}{$\begin{array}{l}\text { Changes in } \\
\text { intervention group, } \\
n=165\end{array}$} & \multicolumn{2}{|c|}{$\begin{array}{l}\text { Changes in control } \\
\text { group, } n=149\end{array}$} & \multirow{2}{*}{$\begin{array}{l}\mathrm{p} \text { Value } \\
\text { T2 } \ddagger \\
\end{array}$} \\
\hline & & At $\mathrm{T1}^{*} \boldsymbol{\dagger}$ & At T2* & At T1* $\dagger$ & At T2* & \\
\hline & Participants with negative change (\%) & $25(20.2)$ & $31(19.1)$ & $19(16.0)$ & $26(17.6)$ & \\
\hline \multicolumn{7}{|c|}{ Enjoyment brown rice } \\
\hline & Participants with positive change (\%) & $34(27.6)$ & $32(20.4)$ & $20(17.2)^{\star}$ & $27(18.5)$ & 0.140 \\
\hline & Participants with negative change (\%) & $10(8.1)$ & $15(9.6)$ & $7(6.0)$ & $6(4.1)$ & \\
\hline \multicolumn{7}{|c|}{ Enjoyment snacks§ } \\
\hline & Participants with positive change (\%) & $25(20.5)$ & $22(13.9)$ & $24(20.3)$ & $19(12.9)$ & 0.147 \\
\hline & Participants with negative change (\%) & $36(29.5)$ & $49(31.0)$ & $16(13.6)$ & $32(21.8)$ & \\
\hline \multicolumn{7}{|c|}{$\begin{array}{l}\text { Perceiving social Physical activity } \\
\text { support }\end{array}$} \\
\hline \multicolumn{7}{|c|}{ Partner } \\
\hline & Participants with positive change (\%) & $18(14.2)$ & $28(17.0)$ & $13(10.7)$ & $22(14.8)$ & 0.730 \\
\hline & Participants with negative change (\%) & $13(10.2)$ & $16(9.7)$ & $11(9.1)$ & $12(8.1)$ & \\
\hline \multicolumn{7}{|c|}{ Others } \\
\hline & Participants with positive change (\%) & $26(20.3)$ & $30(18.2)$ & $19(15.7)$ & $28(18.8)$ & 0.205 \\
\hline & Participants with negative change (\%) & $18(14.1)$ & $15(9.1)$ & $16(13.2)$ & $23(15.4)$ & \\
\hline & \multicolumn{6}{|l|}{ Diet } \\
\hline & \multicolumn{6}{|l|}{ In general } \\
\hline & Participants with positive change (\%) & $21(16.5)$ & $28(17.1)$ & $19(16.1)$ & $27(18.1)$ & 0.090 \\
\hline & Participants with negative change (\%) & $21(15.5)$ & $35(21.3)$ & 27 (22.9) & $18(12.1)$ & \\
\hline & \multicolumn{6}{|l|}{ Brown rice } \\
\hline & Participants with positive change (\%) & $28(22.2)$ & $26(15.9)$ & $17(14.4)$ & $31(20.8)$ & 0.473 \\
\hline & Participants with negative change (\%) & $12(9.5)$ & $24(14.6)$ & $22(18.6)$ & $18(12.1)$ & \\
\hline & \multicolumn{6}{|l|}{ Refusing snacks } \\
\hline & Participants with positive change (\%) & $30(23.6)$ & $37(22.6)$ & $18(15.1)^{\star}$ & $37(25.0)$ & 0.389 \\
\hline & Participants with negative change (\%) & $13(10.2)$ & $29(17.7)$ & $25(21.0)$ & $18(12.2)$ & \\
\hline \multirow{13}{*}{$\begin{array}{l}\text { Perceiving self- } \\
\text { efficacy }\end{array}$} & Physical activity & & & & & \\
\hline & Participants with positive change (\%) & $22(17.2)$ & $28(17.0)$ & $18(14.9)$ & $25(16.8)$ & 0.973 \\
\hline & Participants with negative change (\%) & $24(18.8)$ & $19(11.5)$ & $14(11.6)$ & $16(10.7)$ & \\
\hline & \multicolumn{6}{|l|}{ Diet } \\
\hline & \multicolumn{6}{|l|}{ In general } \\
\hline & Participants with positive change (\%) & $4(3.1)$ & $7(4.2)$ & $7(5.8)$ & $10(6.7)$ & $0.334^{\star *}$ \\
\hline & Participants with negative change (\%) & $2(1.6)$ & $3(1.8)$ & $7(5.8)$ & $4(2.7)$ & \\
\hline & \multicolumn{6}{|l|}{ Brown rice } \\
\hline & Participants with positive change (\%) & $28(21.7)$ & $26(15.9)$ & $29(24.0)$ & $27(18.1)$ & 0.669 \\
\hline & Participants with negative change (\%) & $22(17.1)$ & $20(12.2)$ & $13(10.7)$ & $14(9.4)$ & \\
\hline & \multicolumn{6}{|l|}{ Refusing snacks } \\
\hline & Participants with positive change (\%) & $25(20.0)$ & $40(24.8)$ & $25(21.4)$ & $27(18.9)$ & 0.359 \\
\hline & Participants with negative change (\%) & $11(8.8)$ & $15(9.3)$ & $14(12.0)$ & $18(12.6)$ & \\
\hline $\begin{array}{l}\text { Stage of } \\
\text { change- } \\
\text { motivated to } \\
\text { change }\end{array}$ & Physical activity within 6 months & & & & & \\
\hline & Participants with positive change (\%) & 26 (15.8) & $33(20.0)$ & $16(10.7)$ & $21(14.1)$ & 0.076 \\
\hline
\end{tabular}




\begin{tabular}{|c|c|c|c|c|c|}
\hline & \multicolumn{2}{|c|}{$\begin{array}{l}\text { Changes in } \\
\text { intervention group, } \\
n=165\end{array}$} & \multicolumn{2}{|c|}{$\begin{array}{l}\text { Changes in control } \\
\text { group, } n=149\end{array}$} & \multirow{2}{*}{$\frac{\text { p Value }}{\text { T2 } \ddagger}$} \\
\hline & At $\mathrm{T1}^{*} \boldsymbol{\dagger}$ & At T2* & At $\mathrm{T1}^{*} \boldsymbol{\dagger}$ & At T2* & \\
\hline Participants with negative change (\%) & $43(26.1)$ & $30(18.2)$ & $44(29.5)$ & $18(12.1)$ & \\
\hline \multicolumn{6}{|l|}{ Diet within 6 months } \\
\hline Participants with negative change (\%) & $1(0.8)$ & $3(1.8)$ & 4 (3.3) & $4(2.7)$ & \\
\hline \multicolumn{6}{|l|}{ Brown rice } \\
\hline Participants with positive change (\%) & $22(17.2)$ & $21(12.7)$ & $23(19.0)$ & $26(17.4)$ & 0.266 \\
\hline Participants with negative change (\%) & $13(10.2)$ & $30(18.2)$ & $17(14.0)$ & $19(12.8)$ & \\
\hline
\end{tabular}

*Changes from T0 to T1 and T0 to T2 are described as number (percentage of total population) with a positive change (eg, from non-adherent to adherent to the guideline for fruit intake) or a negative change (eg, from a regular to an irregular meal pattern) at 1 and 2 years. The remaining participants had not changed their dietary intake or physical activity.

†Of the 314 participants with a measurement at baseline and at 2-year follow-up, 279 also attended the measurement at 1-year follow-up (148 in the intervention group and 131 in the control group).

$\neq \mathrm{p}$ Value for the intention-to-treat analysis of the difference in changes from T0 to T2 between the intervention and control group.

$\S S i x$ common risk factors: overweight, too little exercise, unhealthy diet, age $\geq 35$ years, smoking and hypertension.

||Except for the belief that masala intake is a possible cause of diabetes and the attitude toward refusing snacks at parties, an increase or positive change in the items measuring the determinants of behaviour change was expected to positively influence behaviour change.

**Because of low expected counts, a Fisher's exact test or chi-square test was done comparing the category positive change versus the rest. T0, baseline measurement; T1, measurement after 1 year; T2, measurement after 2 years; T2D, type 2 diabetes mellitus.

groups). Similar to the results for dietary behaviour and physical activity, remarkably high percentages of participants showed a 'negative' change in social-cognitive determinants.

\section{DISCUSSION}

This study examined the effect of a culturally targeted intervention on dietary behaviour and physical activity among a South Asian population at risk for T2D. At 2-year follow-up, no significant difference was found between the intervention and control groups in changes in any of the components of dietary and physical activity behaviour or in the social-cognitive determinants underlying these behaviours. Notably, in both groups, the proportion of participants reporting a less healthy behaviour at 2-year follow-up almost equalled the proportion reporting a more healthy behaviour. The percentage of participants lost to follow-up was high.

\section{Study limitations}

In addition to a relatively low response rate for the initial screening and for the baseline evaluation, a relatively high number of participants dropped out of the study. This low participation rate limits the reach and potential impact that the intervention may have in practice. In addition, we are aware that selective drop-out may lead to a biassed estimate of intervention effects. However, analysis of the characteristics of those who dropped out and the evaluation of patterns of missingness provided no clear evidence on the direction in which our estimates may have been biassed. This is in line with our previous analyses on the longitudinal DHIAAN data at 1-year follow-up that showed no relevant contribution of multiple imputations to the interpretation of our data. ${ }^{14}$ Nevertheless, it seems fair to consider the high drop-out rate as a sign that for many participants the intervention did not meet their perceived needs.

In the interpretation of our results, it should also be noted that self-reported questionnaire data were used to assess the change in physical activity, diet and the determinants of behaviour change. We cannot exclude the possibility that our participants gave socially desirable answers, ${ }^{39}$ potentially influenced by an increase in awareness after the start of the intervention. As recommended, we added culturally specific activities to the physical activity questionnaire (such as yoga and dancing) to mitigate cultural differences in recommended physical activity $^{35}$; nevertheless, the validity of this measurement may have been suboptimal. To measure diet, we included a limited number of questions on specific behaviours, which may be less reliable than biomarkers or a more complete measurement of food intake such as a food frequency questionnaire. ${ }^{40}{ }^{41}$ As a result, we may have missed more general positive changes in other aspects of the diet, potentially due to the intervention.

In addition, because the reference period for the physical activity and diet questionnaire spanned a few months, the answers may have been influenced by recall bias. ${ }^{40}$ Although the effect of these types of bias apply to both groups, the effects could differ between the groups, for example, due to the focus on certain behaviours during the intensive counselling in the intervention group. 
However, this seems very unlikely given the small differences between the two groups in reported changes. Therefore, we conclude that it is unlikely that these methodological limitations have substantially biased the present results.

\section{Discussion of main findings}

At 2-year follow-up, we found that a culturally targeted lifestyle intervention in primary care did not change the dietary behaviour and physical activity of a group of South Asian people at risk for T2D. This is in line with our observation of no effect of the intervention on weight status and other metabolic risk factors at 1-year follow-up. ${ }^{14}$ However, a lack of effect on metabolic outcomes at 1 year does not rule out the possibility that the health behaviours or the underlying determinants may still change due to the intervention. The results of the present study suggest that this was not the case. On the contrary, the health behaviour of a substantial number of participants even deteriorated. This was unexpected given the intensity of our intervention, an element previously shown to increase the effectiveness of such a lifestyle programme. ${ }^{42}$ Although changes in reported behaviour may also be the result of increased awareness among participants of their own (poor) diet and physical activity, the negative finding matches the weight gain reported for some participants after 1 year of follow-up. ${ }^{14}$

There are several possible reasons for the lack of an effect of the intervention on health behaviour. First, despite being classified as being at risk for diabetes (ie, impaired glucose tolerance, impaired fasting glucose or relatively high insulin resistance), the participants were relatively healthy and health conscious. For instance, the mean BMI was lower compared with other, similar, populations. ${ }^{2-4}$ 6-8 Moreover, a substantial part of our population met the guidelines for a healthy diet at baseline and indicated that they considered physical activity and a healthy diet important. These positive characteristics probably leave little room for improvement with an intervention aimed at a healthy lifestyle alone. To effectively reduce the burden of T2D among South Asians, future interventions should explore new strategies, for example, focus on more specific forms of physical activity. ${ }^{43}$ In addition, the low initial response rate in combination with the high drop-out rate raises the question whether an intensive intervention as employed in this study is the optimal approach to reach those in need in this high-risk population. It suggests that, despite all efforts to adapt the intervention, the current design is not attractive and acceptable to the target population. More acceptable interventions that reach a larger proportion of those with an increased risk of T2D seem necessary in order to effectively reduce the risk of T2D at population level. This might include more community-engaged interventions. Broader involvement from the community as a whole, perhaps in an even earlier phase of the project or in different aspects, might improve the acceptability and enhance the response to the intervention. Nevertheless, the current project builds on a long tradition of health interventions by the Municipal Health Service of the Hague (BM). Moreover, we have tried to engage community members and professionals in the adaptation of the intervention during the pilot. ${ }^{20}$

Second, the intervention primarily addressed the individual and only marginally targeted the individual's environment. However, changes in the physical and social environment may necessary to influence the accessibility to and the social norm toward a healthy lifestyle, making it easier to make healthier lifestyle choices. ${ }^{18}{ }^{44}$ For instance, evidence from the Ensemble, Prévenons l'Obesité Des Enfants approach suggests that environmental changes implemented by the private and public sectors are essential for behaviour change in the long term. ${ }^{45} \mathrm{We}$ attempted to make the intervention accessible by offering a local physical activity programme and having dieticians carry out the intervention as part of their dietician practice. However, we did not involve the private and public sectors to make adjustments to the immediate environment to facilitate healthier lifestyle choices, for example, in local (South Asian) supermarkets or at work. In that case, the intervention might have benefited from support for the intended behaviour changes via changes in the environment. This explanation is supported by data from similar interventions in a primary care setting ${ }^{6-846}$ that also failed to positively change health behaviour. For instance, an intervention study in a Dutch primary care setting reported a significant difference between the groups only for physical activity and fibre intake. ${ }^{6}$ At the same time, we should be cautious in our expectations. Previous research indicates that the dietary patterns of South Asian Surinamese are rather robust across acculturation strategies. More specifically, South Asian Surinamese participants reported significantly higher intakes of rice (staple food) and chicken (complementary food) and significantly lower intakes of red meat and vegetables (complementary foods) and cookies and sweets (accessory food) as compared with the host population. ${ }^{47}$ The robustness of these patterns probably suggests that a single intervention will not suffice to change these patterns.

Third, the intervention as implemented may not have met the needs of our specific population. This might partly be due to a suboptimal implementation of the targeted intervention. We, for example, found that the adapted counselling method-using the principles of motivational interviewing - had not been fully applied during the sessions of the dieticians. ${ }^{48}$ The difficulties that we experienced with application of this method have also been reported in other studies (eg, Noordman $e t a l^{49}$ ). Hence, one might question whether professionals in practice can be expected to show motivational interviewing skills in this kind of interventions as long as these skills are not a fully integrated part of the baseline qualifications of these professionals. Moreover, although we purposefully invested in culturally targeting the intervention and the majority of participants perceived the materials as clear and attractive, we cannot rule out the 
possibility that further investments or investments in other elements could have improved the effectiveness of the interventions. This also applies to the choice for the technique of motivational interviewing. The experiences of some dieticians seemed to indicate that this technique was less effective for this South Asian origin population, as some participants preferred a more directive style and 'just wanted a list what to do or what to eat'. ${ }^{48}$ Additionally, few participants took up the offer of a family session. This seems in contrast with the success of family-oriented sessions in a comparable trial among South Asians in the UK. ${ }^{15}$ This difference between both trials might indicate the importance of involvement of the family from the start of the intervention, rather than in a separate family session. ${ }^{47}$ On the other hand, it might also reflect real differences between the South Asian population in the UK and that in the Netherlands. As the latter have migrated via Surinam, a former Dutch colony, this might have led to a situation where they have been more adapted to the host culture than the South Asians in the UK. More studies are needed to elucidate the specific elements which make cultural targeting effective in this population. ${ }^{50}$

\section{CONCLUSIONS}

In this group of South Asians (aged 18-60 years) at risk for diabetes, a culturally targeted lifestyle intervention was not effective in promoting healthy behaviour. At 2-year follow-up, the changes in dietary behaviour, physical activity or underlying social-cognitive determinants in the intervention group did not differ from those in the control group. Given the high a priori risk and the specific characteristics of the target population, we recommend further research to determine whether an updated strategy, preferably more acceptable for the target population, may change health behaviours through changes in the underlying social-cognitive determinants (eg, social norms and self-efficacy) in this high-risk South Asian population.

Contributors EV and IV analysed the data. EV contributed to the interpretation and drafted the first version of the manuscript. IV and KS designed the study, contributed to the interpretation of the data and edited the manuscript. VN, BJCM and $\mathrm{MN}$ gave advice for the design and interpretation. WB contributed to the analysis and interpretation. All authors reviewed the manuscript and approved the final version.

Funding This study was funded by the Netherlands Organisation for Health Research and Development (ZonMw; grant no.120620023).

Competing interests None declared.

Ethics approval Institutional Review Board of the Academic Medical Center of the University of Amsterdam.

Provenance and peer review Not commissioned; externally peer reviewed.

Data sharing statement № additional data supporting the present paper are available online. Data collected during the study, as described in doi: $10.1186 / 1471824588128371$, after a collaboration agreement is signed. Researchers may contact i.g.vanvalkengoed@amc.nl or k.stronks@amc.nl.

Open Access This is an Open Access article distributed in accordance with the Creative Commons Attribution Non Commercial (CC BY-NC 4.0) license, which permits others to distribute, remix, adapt, build upon this work non-commercially, and license their derivative works on different terms, provided the original work is properly cited and the use is non-commercial. See: http://creativecommons.org/ licenses/by-nc/4.0/

(C) Article author(s) (or their employer(s) unless otherwise stated in the text of the article) 2017. All rights reserved. No commercial use is permitted unless otherwise expressly granted.

\section{REFERENCES}

1. Zimmet PZ. Primary prevention of diabetes mellitus. Diabetes Care 1988;11:258-62.

2. Roumen C, Corpeleijn E, Feskens EJ, et al. Impact of 3-year lifestyle intervention on postprandial glucose metabolism: the SLIM study. Diabet Med 2008;25:597-605.

3. Knowler WC, Barrett-Connor E, Fowler SE, et al. Reduction in the incidence of type 2 diabetes with lifestyle intervention or metformin. N Engl J Med 2002;346:393-403.

4. Tuomilehto J, Lindström J, Eriksson JG, et al. Prevention of type 2 diabetes mellitus by changes in lifestyle among subjects with impaired glucose tolerance. N Engl J Med 2001;344:1343-50.

5. Ramachandran A, Snehalatha C, Mary S, et al. The Indian Diabetes Prevention Programme shows that lifestyle modification and metformin prevent type 2 diabetes in Asian Indian subjects with impaired glucose tolerance (IDPP-1). Diabetologia 2006;49:289-97.

6. Vermunt PW, Milder IE, Wielaard F, et al. Lifestyle counseling for type 2 diabetes risk reduction in Dutch primary care: results of the APHRODITE study after 0.5 and 1.5 years. Diabetes Care 2011;34:1919-25.

7. Kontogianni MD, Liatis S, Grammatikou S, et al. Changes in dietary habits and their association with metabolic markers after a nonintensive, community-based lifestyle intervention to prevent type 2 diabetes, in Greece. the DEPLAN study. Diabetes Res Clin Pract 2012;95:207-14.

8. Kujala UM, Jokelainen $\mathrm{J}$, Oksa $\mathrm{H}$, et al. Increase in physical activity and cardiometabolic risk profile change during lifestyle intervention in primary healthcare: 1-year follow-up study among individuals at high risk for type 2 diabetes. BMJ Open 2011;1:e000292.

9. Wild S, Roglic G, Green A, et al. Global prevalence of diabetes: estimates for the year 2000 and projections for 2030. Diabetes Care 2004;27:1047-53.

10. Kanaya AM, Wassel CL, Mathur D, et al. Prevalence and correlates of diabetes in South Asian Indians in the United States: findings from the metabolic syndrome and atherosclerosis in South Asians living in America study and the multi-ethnic study of atherosclerosis. Metab Syndr Relat Disord 2010;8:157-64.

11. Gholap N, Davies M, Patel K, et al. Type 2 diabetes and cardiovascular disease in South Asians. Prim Care Diabetes 2011;5:45-56.

12. Bindraban NR, van Valkengoed IG, Mairuhu G, et al. Prevalence of diabetes mellitus and the performance of a risk score among Hindustani Surinamese, African Surinamese and ethnic Dutch: a cross-sectional population-based study. BMC Public Health 2008;8:271.

13. Misra A, Ganda OP. Migration and its impact on adiposity and type 2 diabetes. Nutrition 2007;23:696-708.

14. Admiraal WM, Vlaar EM, Nierkens V, et al. Intensive lifestyle intervention in general practice to prevent type 2 diabetes among 18 to 60 -year-old South Asians: 1-year effects on the weight status and metabolic profile of participants in a randomized controlled trial. PLoS One 2013;8:e68605.

15. Bhopal RS, Douglas A, Wallia S, et al. Effect of a lifestyle intervention on weight change in south Asian individuals in the UK at high risk of type 2 diabetes: a family-cluster randomised controlled trial. Lancet Diabetes Endocrinol 2014;2:218-27.

16. Weber MB, Oza-Frank R, Staimez LR, et al. Type 2 diabetes in Asians: prevalence, risk factors, and effectiveness of behavioral intervention at individual and population levels. Annu Rev Nutr 2012;32:417-39.

17. Rosenstock IM. The health belief model and nutrition education. $J$ Can Diet Assoc 1982;43:184-92.

18. Ajzen I. The theory of planned behaviour: reactions and reflections. Psychol Health 2011;26:1113-27.

19. Prochaska JO, Johnson S, Lee P, et al. The transtheoretical model of behavior change. the handbook of health behavior change. 2nd edn. New York: Springer Publishing Co, 1998:59-84.

20. Vlaar EM, van Valkengoed IG, Nierkens V, et al. Feasibility and effectiveness of a targeted diabetes prevention program for 18 to 60-year-old South Asian migrants: design and methods of the DH!AAN study. BMC Public Health 2012;12:371. 
21. Choenni C, Harmsen C. Place of birth and ethnic composition of the Surinamese in the Netherlands in Dutch. Bevolkingtrends 2007;1:74-8.

22. Nicolaou M, Vlaar E, van Valkengoed I, et al. Development of a diabetes prevention program for Surinamese South Asians in the Netherlands. Health Promot Int 2014;29:680-91.

23. Mensink M, Corpeleijn E, Feskens EJ, et al. Study on lifestyleintervention and impaired glucose tolerance maastricht (SLIM): design and screening results. Diabetes Res Clin Pract 2003;61:49-58.

24. Bartholomew LK, Parcel GS, Kok G, et al. Planning health promotion programs. An intervention mapping approach. . 3th edn. San Francisco, CA: Jossey-Bass, 2011:19. 171-306.

25. Health council of the netherlands. Guidelines for a healthy diet: the ecological perspective. The Hague: Health Council of the Netherlands, 2011.

26. Resnicow K, Baranowski T, Ahluwalia JS, et al. Cultural sensitivity in public health: defined and demystified. Ethn Dis 1999;9:10-21.

27. Kemper HCG, Ooijendijk WTM, Stiggelbout M. Concensus over de nederlandse norm voor gezond bewegen. Tijdschrift voor Gezondheidswetenschappen 2000;78:180-3.

28. Resnicow K, McMaster F. Motivational interviewing: moving from why to how with autonomy support. Int J Behav Nutr Phys Act 2012;9:19.

29. Hosper K, Deutekom M, Stronks K. The effectiveness of "Exercise on Prescription" in stimulating physical activity among women in ethnic minority groups in the Netherlands: protocol for a randomized controlled trial. BMC Public Health 2008;8:406.

30. Schmidt M, Absalah S, Nierkens V, et al. Which factors engage women in deprived neighbourhoods to participate in exercise referral schemes? BMC Public Health 2008;8:371.

31. Gademan MG, Deutekom M, Hosper K, et al. The effect of exercise on prescription on physical activity and wellbeing in a multi-ethnic female population: a controlled trial. BMC Public Health 2012;12:758

32. Matthews DR, Hosker JP, Rudenski AS, et al. Homeostasis model assessment: insulin resistance and beta-cell function from fasting plasma glucose and insulin concentrations in man. Diabetologia 1985;28:412-9.

33. Vlaar EM, Nierkens V, Nicolaou M, et al. Risk perception is not associated with attendance at a preventive intervention for type 2 diabetes mellitus among south asians at risk of diabetes. Public Health Nutr 2015;18:1109-18.

34. Wendel-Vos GC, Schuit AJ, Saris WH, et al. Reproducibility and relative validity of the short questionnaire to assess health-enhancing physical activity. J Clin Epidemiol 2003;56:1163-9.

35. de Munter JS, van Valkengoed IG, Agyemang C, et al. Large ethnic variations in recommended physical activity according to activity domains in amsterdam, the Netherlands.. Int J Behav Nutr Phys Act 2010;7:85.
36. Leventhal H, Kelly K, Leventhal EA. Population risk, actual risk, perceived risk, and cancer control: a discussion. J Natl Cancer Inst Monogr 1999:81-5.

37. Lindström J, Tuomilehto J. The diabetes risk score: a practical tool to predict type 2 diabetes risk. Diabetes Care 2003;26:725-31.

38. Claassen L, Henneman L, van der Weijden T, et al. Being at risk for cardiovascular disease: perceptions and preventive behavior in people with and without a known genetic predisposition. Psychol Health Med 2012;17:511-21.

39. Shephard RJ. Limits to the measurement of habitual physical activity by questionnaires. Br J Sports Med 2003;37:197-206.

40. Kremers SP, Visscher TL, Seidell JC, et al. Cognitive determinants of energy balance-related behaviours: measurement issues. Sports Med 2005;35:923-33.

41. Verschuren $\mathrm{P}$, Doorewaard H. Designing a research project, 1 edition. Utrecht, The Netherlands: Lemma, 2005:125-69.

42. Balk EM, Earley A, Raman G, et al. Combined diet and physical activity promotion programs to prevent type 2 diabetes among persons at increased risk: a systematic review for the community preventive services task force. Ann Intern Med 2015;163:437-51.

43. Tresierras MA, Balady GJ. Resistance training in the treatment of diabetes and obesity: mechanisms and outcomes. J Cardiopulm Rehabil Prev 2009;29:67-75.

44. Netherlands Organisation for Health Research and Development. In: Brug J, van Lenthe F, eds. Environmental determinants and interventions for physical activity, nutrition and smoking: a review. 2005.

45. Romon M, Lommez A, Tafflet M, et al. Downward trends in the prevalence of childhood overweight in the setting of 12-year school- and community-based programmes. Public Health Nutr 2009;12:1735-42.

46. Aziz Z, Absetz P, Oldroyd J, et al. A systematic review of real-world diabetes prevention programs: learnings from the last 15 years. Implement Sci 2015;10:172.

47. Raza Q, Nicolaou M, Snijder MB, et al. Dietary acculturation among the South-Asian surinamese population in the Netherlands: the HELIUS study. Public Health Nutr 2016;28:1-10.

48. Vlaar L. Feasibility and effectiveness of a culturally targeted diabetes prevention program among South Asians in Dutch primary care. The DH!AAN-study. Amsterdam: University of Amsterdam. PhD thesis, 2014.

49. Noordman J, van Lee I, Nielen M, et al. Do trained practice nurses apply motivational interviewing techniques in primary care consultations? J Clin Med Res 2012;4:393-401.

50. Nierkens V, Hartman MA, Nicolaou M, et al. Effectiveness of cultural adaptations of interventions aimed at smoking cessation, diet, and/or physical activity in ethnic minorities. a systematic review. PLoS One 2013;8:e73373. 